\title{
云南景洪县怕冷橄榄岩一闪长岩型杂岩的 地球化学特征及其构造意义
}

\author{
赵大升张旗 \\ （中国科学院地质研究所,北京 100029） \\ 王明 新 \\ （云南省地质㖶产局第五地质大队，思茅 665000） \\ 黄忠样 韩 松 贾秀芹 董金泉 \\ (中国科学完高能物理研究所, 北京 100080 )
}

\section{关镜调橔模岩一内长岩型、地球化学、景洪}

云南褁洪地区临沧花岗岩基南段的东侧, 出露有许多小规模的长英质至超镁铁质的杂岩 体, 其中以花岗岩和闪长岩数量最多, 规模也较大, 辉长岩较少 (部分单独出现, 另一部分产于 内长岩体内部), 辉石岩和檄榄岩的规模和数量更小, 且无例外地被包裹在闪长岩体内. 以怕 冷岩体为例, 该岩体呈弯月状产出, 南北最长 $9 \mathrm{~km}$, 东西宽约 $6 \mathrm{~km}$. 岩体西部与晚元古代的阐 沦群接触, 东部被印支期花岗闪长岩侵人 (图 1), 推测是海西-印支期侵位的. 岩体以闪长岩为 主体, 内部包裹几个面积不大的辉长岩、角闪岩、辉石岩及角闪橔榄岩体. 辉长岩长不到 $1 \mathrm{~km}$, 宽仅 200-300m. 辉石岩和䔩榄岩规模更小, 长宽均不到 $200 \mathrm{~m}$, 有的单独出现在闪长岩中, 有的与辉长岩共生在一起, 与辉长岩呈渐变关系. 闪长岩体外围有花岗闪长岩侵人. 因此, 由中 心向外, 可依次出现檄柂岩、晖石岩、辉长岩、闪长岩和花岗闪长岩, 而具环状分布的特征. 这 种超镁铁一长英质的岩石组合, 类似美国西部克拉玛斯山和加利福尼亚的 Bear 山和 Emigrant Gap. 岩体. 相当于 Snoke 等“划分的“檄榄岩一闪长岩”型杂岩. 该类型杂岩体通常呈环状 分布, 产于禺弧或活动大陆边缘环境, 常与大的花岗岩基伴生, 属钙碱系列. 有人认为这类岩 体与火山弧安山岩有成因上的联系, 是火山弧根部的岩石. 这类岩体在国内还很少报道过.

怕冷岩体中产出的角闪橔榄岩、辉石岩、角闪石岩和辉长岩均发育堆晶结构. 角闪檄榄岩 中自形的㮹嘴石(已全部蛇纹石化)被角闪石包裹, 有的角闪石中可包裹一至三个橄榄石晶粒, 为异补堆晶结构. 檄榄石蚀变后析出较多的磁铁矿, 呈网纹状分布, 指示原先的㮹政石可能是 富 $\mathrm{Fe}$ 质的. 角闪石自形至半自形, 含量占 $30 \%$ 左右, 为原生矿物, 表明原始岩浆是富 $\mathrm{H}_{2} \mathrm{O}$ 的. 辉长岩和闪长岩的主要组成矿物相似, 均以角闪石和斜长石为主, 几乎见不到钾长石. 区 别在于内长岩中有时有少量石英存在及斜长石牌号偏低(中-更长石).

主元素、微量元素 (包括稀土元素) 化学分析表明, 无论是檄榄岩或闪长岩, 都是贫 $\mathrm{K}$ 的, $\mathrm{K}_{2} \mathrm{O}$ 含量不高于 $0.47 \%$, 这与镜下几乎见不到钾长石一致, 暗示该类岩石可能来源于地幔. 杂岩体中角闪檄榄岩的 $\mathrm{MgO}$ 含量高, 为 $29 \%$, 但 $\mathrm{FeO}$ 含量也相当的高 $\left(\mathrm{FeO}+\mathrm{Fe}_{2} \mathrm{O}_{3}=\right.$ $13.88 \%$ ), 因而它的 $\mathrm{Mg}^{\prime}$ 值并不高, 仅为 0.80 , 代表一种富 $\mathrm{Fe}$ 质的檄榄岩类. 辉石岩和角闪石

本文 1990 年 5 月 3 日收到. 
岩富 Cr 贫 Ni, REE 分布为 LREE 富集型的, 无 $\mathrm{Eu}$ 异常(图 2 中的 No.5、6、7), 类似于美国 西部 Bear 山辉石岩的 REE 型式[2. 辉长岩的 $\mathrm{Al}_{2} \mathrm{O}_{3}$ 和 $\mathrm{TiO}_{2}$ 含量变化大 (分别为 $14-18.7 \%$ 和 $0.23-2.03 \%), \mathrm{Al}_{2} \mathrm{O}_{3}$ 变化大暗示受斜长石

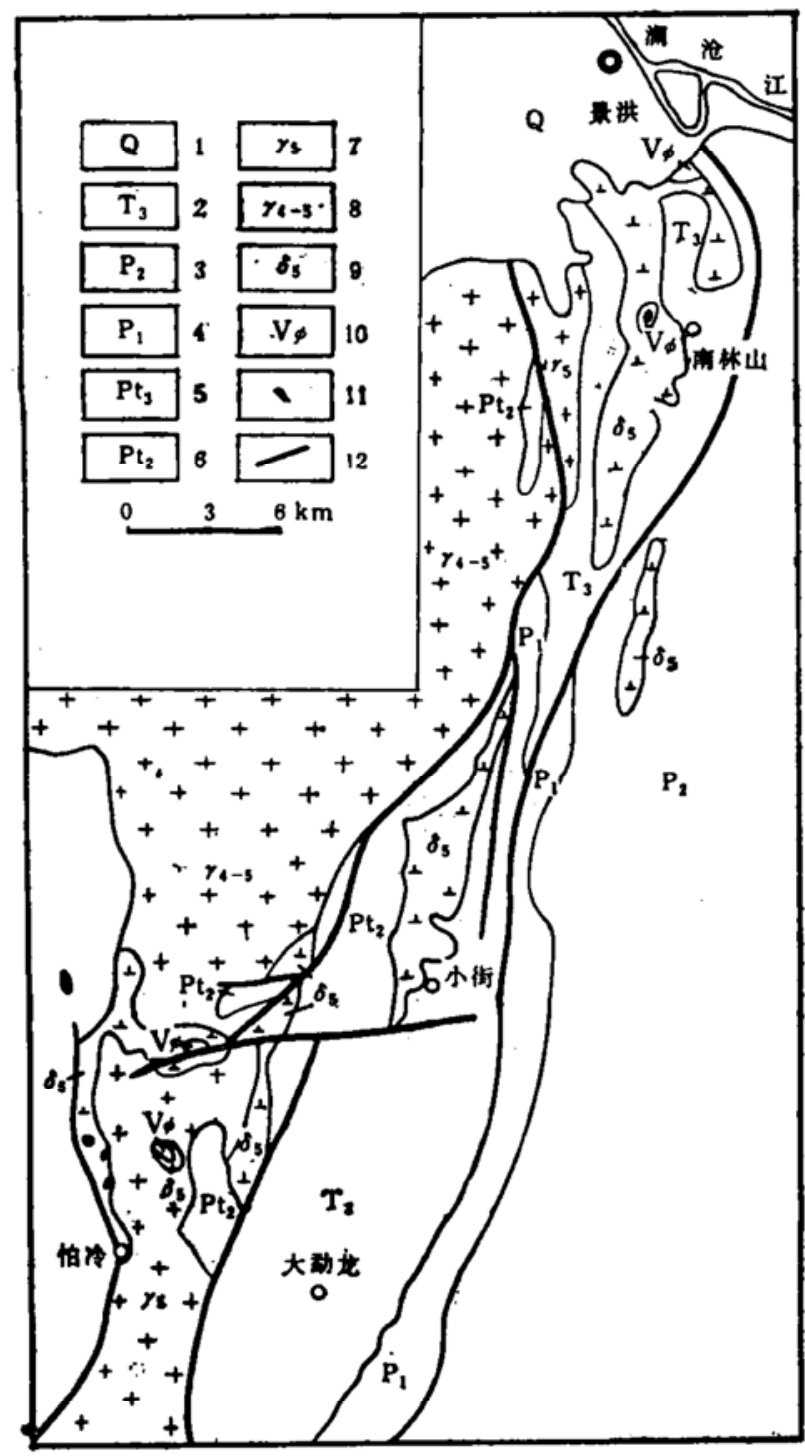

图 1 饪冷岩体区域地质略图

1.第四系；2.上三叠系；3.上二叠系；4.下二童系； 5. 晚元古界润沧群；6.中元古界大预龙群；7. 印支期 花岗岩；8.海西-印支期花岗岩；9.印支期以长岩; 10.浑长岩; 11.超镁铁岩; 12.断层

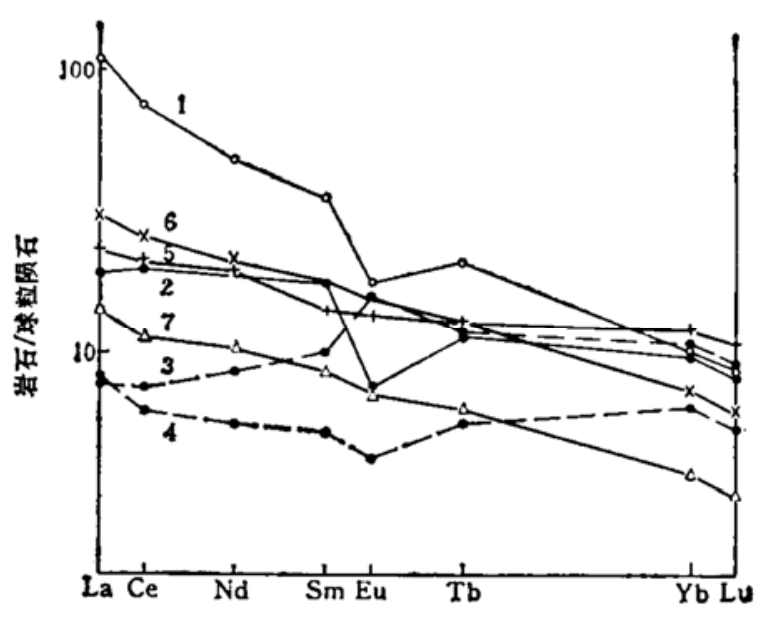

图 2 饪冷岩体各类岩石的 REE 分布型式 1. 花岗岩；2. 内长岩；34.辉长岩；5.角队石岩；67. 晖石岩

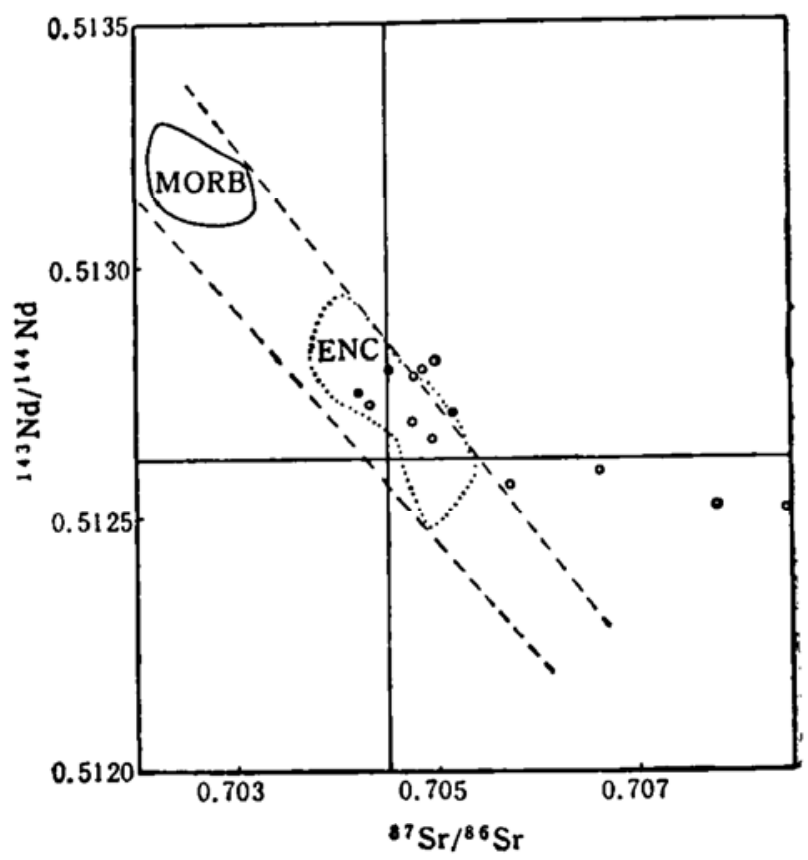

图 $3{ }^{143} \mathrm{Nd} /{ }^{144} \mathrm{Nd}$ 与 "Sr $/{ }^{80 S r}$ 相关图 ○为印度尼西亚第四纪熔岩; - 为伯冷岩体投影点; ENC 为中国东北及华北新生代钠质火山岩投影区; MORB 为洋中学玄武岩投影区; 虚线范围示地演化 范围

数量的控制. 辉长岩微量元素的共同特征是 $\mathrm{Sr}$ 高 $(390-445 \mathrm{ppm}$, 下同) 和 $\mathrm{Zr}$ 低(20-54 $\mathrm{ppm}), \mathrm{Sr}$ 高指示岩石中钙长石的含量丰富, $\mathrm{Zr}$ 低则表明辉长岩是堆晶成因的. 值得注意的 是辉长岩的 REE 型式变化大, 如图 2 中的 No. 3、4, 分别为 LREE 和 MREE 亏损型的, 与 同一岩体中的辉石岩和角闪石岩都不一样. 看来, 同被包裹在怕冷闪长岩中的镁铁和超镁铁 岩具有复杂的成因. 怕冷闪长岩的 $\mathrm{Mg}^{\prime}$ 值低 (0.39-0.58); LREE 略富集, 具明显的负 $\mathrm{Eu}$ 异 常 $\left(\mathrm{Eu} / \mathrm{Eu}^{*}-0.56\right)$, 从图 2 中看出, 闪长岩 (No.2) 的 $\Sigma \mathrm{REE}$ 丰度与角闪石岩 (No.5) 及 挥石岩 (No.6) 相当,看来,闪长岩不大可能是辉石岩和角闪石岩分离结晶作用的产物. 
怕冷岩体边部的花岗闪长岩和花岗岩, 其地球化学行为明显不同于内长岩一袘梅岩组合. 花岗闪长岩和花岗岩 $\mathrm{K}_{2} \mathrm{O}$ 的丰度高 $(2.16-4.41 \%), \Sigma R E E$ 丰度也是最高的, 并且 LREE 强 烈富集 $\left(\mathrm{La}_{N} / \mathrm{Yb}_{N}-11.4\right)$ ，具明显的负 $\mathrm{Eu}$ 异常（图 2 的 No.1），与临沦花岗岩基的 REE 分布型式相似.

上述情况表明,怕冷岩体的岩石类型及其成因是复杂的. 这在 Sr 和 $\mathrm{Nd}$ 同位素成分上 也十分明显. 怕冷岩体的 ${ }^{87} \mathrm{Sr} /{ }^{86} \mathrm{Sr}$ 初始比值变化较大. 从 0.7041 至 0.7073 , 指示受蚀变作用 和陆壳混染的影响. 若与现今上地幔 ${ }^{87} \mathrm{Sr} /{ }^{86} \mathrm{Sr}$ 初始比值 0.702-0.706 相比较, 怕冷岩体的大 部分数值仍在地幔演化范围之内, 暗示它来自上地幔. 这与上述岩体贫 $\mathrm{K}$ 的特征是一致的. 至于个别样品超出现今上地幔 ${ }^{87} \mathrm{Sr} /{ }^{86} \mathrm{Sr}$ 比值范围, 则与陆壳混染或蚀变作用有关. Nd 同位 至测定了三个样品, 包括闪长岩、辉长岩和辉石岩, 其 ${ }^{143} \mathrm{Nd} /{ }^{14} \mathrm{Nd}$ 初始比值变化不大, 在 $0.5121-0.5128$ 之间, $\varepsilon \mathrm{Nd}>0(+1.3-+2.5)$, 看来, 怕冷岩体各类岩石的源区成分是比较 均一的,均属于弱亏损的地幔岩 (与M ORB 相比, ${ }^{43} \mathrm{Nd} /{ }^{144} \mathrm{Nd}$ 比值低和 ${ }^{87} \mathrm{Sr} /{ }^{86} \mathrm{Sr}$ 比值高).

对怕冷岩体测定了 8 个样品的 $S_{\boldsymbol{I}}$ 同位素成分, 未发现存在等时线关系, 点的分散可能表 明原岩并不属于单一的同成因的岩套, 故没有同样的 Sr 初始比值, 这也可能受到陆壳物质的 混染,而干扰了 $\mathrm{Rb} / \mathrm{Sr}$ 比值. REE 分布型式的不同也是一个强有力的证据.

我们知道, 侵人岩尤其是堆晶岩产出的构造环境, 用岩石化学方法是很难确定的, 但是, $\mathrm{Nd}$ 和 $\mathrm{Sr}$ 同位索的特征却与全岩的化学成分无关，只受构造环境的控制河. 从图 3 中看出. ${ }^{87} \mathrm{Sr} /{ }^{86} \mathrm{Sr}$ 比值较高以及 ${ }^{445} \mathrm{Nd} /{ }^{144} \mathrm{Nd}$ 与 ${ }^{87} \mathrm{Sr} /{ }^{86} \mathrm{Sr}$ 不具负相关性, 表明受陆壳混染的影响. ${ }^{8} \mathrm{Nd}$ 为不高的正值, 在图 3 中虽也落在中国东北及华北新生代钠质火山岩息范围内, 但后者的 $\mathrm{ENd}$ 有正值也有负值,且其 $\varepsilon \mathrm{Nd}$ 平均值接近零. 这种情况不同于怕冷岩体. 此外, 从 REE 分布来 看,怕冷岩体也不具有板内火山岩 LREE 强烈富集的型式. 因此, 我们认为, 怕冷岩体并非 产于大陆裂谷环境。相反, 怕冷岩体与印度尼西亚第四纪熔岩的 $\mathrm{Nd}$ 和 $\mathrm{Sr}$ 同位素比值 $\left({ }^{143} \mathrm{Nd} /\right.$ $\left.\left.{ }^{14} \mathrm{Nd}-0.5124-0.5128,{ }^{87} \mathrm{Sr} /{ }^{86} \mathrm{Sr}-0.7042-0.7095\right)\right)^{[3]}$ 比较接近. 暗示怕冷岩体可能产于岛 弧或活动大陆边缘环境.

有限的 Nd 同位索资料表明, 怕冷岩体的源岩具有相对均一的同位素组成, 闪长岩、辉长 岩和辉石岩可能来自于同一源区. 而 S r 同位素的较大变化及主元索和 REE 分布上较大的 差异, 显然是因陆壳物质的加人及混染的程度和规模是不同的. 至于是受洋壳回返或岩浆上 侵时陆壳混染作用的影响,还很难判定. 这也暗示了怕冷岩体形成过程的复杂性。

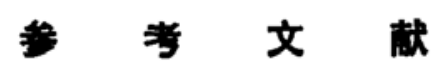

[1] Snoke, A. W. et al., Geology, 10 (1982), 160-166.

[2] Snoke, A. W. et al., J. Petrol., 22(1981), 501-552.

[3] Altherr, R. et al., Earth Planet. Sci. Lett.. 96 (1989), 269-286.

[4] 王俊文等,地球化学, 1988,4: 310-318.

[5] Whitford, D. J. \& White, W. M., Geochim. Cosmochim. Actu, 45 (1981), 989-995. 